\title{
Effect of Magnesium Supplementation to Prevent Nephrotoxicity on the Antitumor Activity of Cisplatin
}

\author{
Megumi Yasuda ${ }^{1}$, Shuichi Kishimoto ${ }^{2,}$, Rika Ebara $^{2}$, Manabu Amano ${ }^{1}$, Shoji Fukushima ${ }^{2}$ \\ ${ }^{1}$ Department of Pharmacy, School of Pharmacy, Hyogo University of Health Sciences, Kobe, Japan \\ ${ }^{2}$ Department of Pharmaceutics, Faculty of Pharmaceutical Sciences, Kobe Gakuin University, Kobe, Japan
}

Email address:

mg-yasuda $a$ huhs.ac.jp (M. Yasuda), skisimot $a$ pharm.kobegakuin.ac.jp (S. Kishimoto)

${ }^{*}$ Corresponding author

To cite this article:

Megumi Yasuda, Shuichi Kishimoto, Rika Ebara, Manabu Amano, Shoji Fukushima. Effect of Magnesium Supplementation to Prevent Nephrotoxicity on the Antitumor Activity of Cisplatin. Journal of Cancer Treatment and Research. Vol. 7, No. 2, 2019, pp. 41-46. doi: $10.11648 /$ j.jctr.20190702.13

Received: August 5, 2019; Accepted: August 24, 2019; Published: September 9, 2019

\begin{abstract}
Background: Cisplatin (CDDP) is one of the most widely used anticancer drugs, but CDDP often leads to nephrotoxicity, which limits its clinical effectiveness. Magnesium (Mg) supplementation is recommended for the avoidance of CDDP-induced nephrotoxicity. However, there is a concern that exposing cancer cells to Mg may suppress the antitumor effect of CDDP. Methods: Transporter expression, intracellular platinum and Mg levels, and cytotoxicity of CDDP after Mg exposure were assessed in human hepatocellular carcinoma (HepG2) and human ovarian carcinoma (2008) cells. Results: In HepG2 cells, Mg exposure significantly increased mRNA levels of multidrug and toxin extrusion 1 (MATE1), which mediates the renal excretion of CDDP, but did not alter its protein levels, including those of organic cation transporter 1 (OCT1), which mediates CDDP uptake in renal tubular and cancer cells, and multidrug resistance-associated protein 2 (MRP2), which mediates CDDP efflux in cancer cells. In 2008 cells, MATE1 protein expression could not be detected, but a slight increase in MRP2 and OCT1 protein expression was observed after $\mathrm{Mg}$ exposure. Intracellular $\mathrm{Mg}$ levels were significantly increased due to $\mathrm{Mg}$ exposure in both cells. However, intracellular platinum levels and cytotoxicity of CDDP were not affected in both cells, even with $2 \mathrm{mM} \mathrm{Mg}$ co-exposure. Conclusion: This study found that $\mathrm{Mg}$ exposure only slightly changed transporter expression and did not affect intracellular platinum levels and CDDP cytotoxicity in HepG2 and 2008 cells. Thus, Mg supplementation can be used to avoid CDDP-induced renal toxicity without affecting the accumulation of CDDP in cancer cells and its cytotoxicity.
\end{abstract}

Keywords: Cisplatin, Magnesium, Transporter, Accumulation

\section{Introduction}

Cisplatin (CDDP) is an anticancer agent containing platinum. CDDP is used to treat different solid cancers such as ovarian cancer, non-small cell lung cancer, bladder cancer, and head and neck cancer. It is also one of the most widely used anticancer drugs and is incorporated into various treatment regimens for preoperative and postoperative adjuvant chemotherapy, advanced cancer and recurrent cancer. CDDP has known side effects such as nephrotoxicity, emetic property, hearing impairment, and peripheral neuropathy. Among them, nephrotoxicity is important and is a dose-limiting factor for CDDP. Various methods for reducing CDDP nephrotoxicity have been studied. Infusion and diuresis before and after
CDDP administration are believed to reduce nephrotoxicity by lowering the concentration of CDDP in urine, thereby shortening the contact time between CDDP and the renal tubule $[1,2]$. Although renal toxicity of CDDP is reduced by infusion, it cannot be completely avoided. Hence, further development of supportive therapy is needed.

Serum magnesium $(\mathrm{Mg})$ has been known to decrease after CDDP administration [3, 4] and is a cationic metal element besides potassium in the human body. It is required for energy production, oxidative phosphorylation, and glycolysis, and it aids in the development of the skeletal system. $\mathrm{Mg}$ is also necessary for the synthesis of DNA, RNA, and the antioxidant, glutathione $[5,6]$. In patients with normal renal function, $\mathrm{Mg}$ is filtered in the glomerulus. $20 \%$ is reabsorbed from the proximal tubule, $70 \%$ from the thick ascending limb of Henle, 
and $5 \%$ from the distal tubule. Hence, only $5 \%$ is excreted in urine. The decrease in serum $\mathrm{Mg}$ observed after CDDP administration is considered to be due to the decrease in $\mathrm{Mg}$ reabsorption associated with tubular damage caused by CDDP $[7,8]$.

In a study of CDDP's impact on renal injury, its effects on transporters were also reported. When kidney tissue sections are cultured in CDDP-containing medium, tissue CDDP concentration is approximately five-fold higher than that found in the medium [9]. In fact, in the proximal tubule of CDDP-treated rats, severe renal damage was observed early after administration [10]. CDDP is carried into the kidney by transporters expressed in the proximal tubule basolateral membrane, thereby causing strong toxicity in the proximal tubule. It accumulates in tubular cells in the kidney via the organic cation transporter (OCT) and is excreted in the tubular lumen via the $\mathrm{H}^{+}$/organic cation transporter, multidrug and toxin extrusion (MATE) [11]. When serum Mg concentration is lowered, the expression level of OCT increases and MATE activity weakens, resulting in excessive accumulation of CDDP in tubular cells, which causes acute kidney injury [12, 13].

In the clinic, $\mathrm{Mg}$ supplementation is performed to prevent renal injury $[14,15]$. Although this supplementation is expected to affect the expression level and activity of transporters in the kidney, ultimately leading to renal accumulation of CDDP [16], it is unclear whether $\mathrm{Mg}$ supplementation may influence the accumulation and antitumor effect of CDDP in cancer cells. In this study, we examined the effect of the combined use of $\mathrm{Mg}$ on cell growth inhibitory effect, intracellular accumulation of CDDP, and transporter expression in two types of cancer cells.

\section{Materials and Methods}

\subsection{Cell Culture}

Human hepatocellular carcinoma (HepG2) cells and human ovarian carcinoma (2008) cells were purchased from Dainippon Pharmaceutical (Osaka, Japan). Cells were maintained in minimum essential medium (Nacalai Tesque, Kyoto, Japan) containing $10 \%$ fetal bovine serum at $37^{\circ} \mathrm{C}$ in humidified air with $5 \% \mathrm{CO}_{2}$.

\subsection{Mg Exposure}

$\mathrm{Mg}$ concentration in the medium containing cells was 0.5 $\mathrm{mM}$. Normal $\mathrm{Mg}$ concentration in human serum is approximately $1 \mathrm{mM}$. In the clinic, $8 \mathrm{mEq}$ of magnesium sulfate is administered to prevent CDDP nephrotoxicity [14]. By considering circulating blood volume, serum magnesium concentration is expected to increase to $\sim 1 \mathrm{mM}$. Therefore, in the $\mathrm{Mg}$-treated group, barium sulfate $(1 \mathrm{mEq} / \mathrm{mL})$ was added to the medium to adjust its $\mathrm{Mg}$ concentration to $2 \mathrm{mM}$.

\subsection{RNA Extraction and Real-time Polymerase Chain Reaction (RT-PCR)}

HepG2 cells or 2008 cells were seeded in $75-\mathrm{cm}^{2}$ tissue culture flasks at a cell density of $1.0 \times 10^{6}$ per flask at $0 \mathrm{~h}$ and then exposed to $2 \mathrm{mM} \mathrm{Mg}$ at $24 \mathrm{~h}$. Immediately after an 8-h exposure to $\mathrm{Mg}$, the cells were harvested and washed three times with cold PBS. Total RNA was extracted using FastGene Premium Kit (NIPPON Genetics, Tokyo, Japan) in accordance with the manufacturer's protocol. The quality and concentration of RNA in each sample was confirmed by spectrophotometry using NanoDrop Lite (Thermo Fisher Scientific, Yokohama, Japan). cDNA was produced from total RNA by reverse transcription using a PrimeScript II First Strand cDNA Synthesis Kit (Takara Bio, Shiga, Japan). Amplification was performed using Rotor-Gene Q (Qiagen, Tokyo, Japan) with a KAPA SYBR Fast qPCR Kit (NIPPON Genetics, Tokyo Japan). Glyceraldehyde 3-phosphate dehydrogenase (GAPDH) was used for normalization of the relative expression levels. The following primers for RT-PCR were synthesized by BEX (Tokyo, Japan): multidrug resistance-associated protein 2 (MRP2), forward 5'-ACGGGCACATCACCATCAAG-3', 5'-CTCCAGGCAGCATTTCCAAG-3'; OCT1, forward 5'-ACTTCATAGCGCCTGCACTG-3', reverse 5'-TCCTCATCTTATGCCTGCTG-3'; MATE1, forward 5'-TGTCACTGGTGTCTCAGTGG-3', reverse 5'-GTAAGCCTGGACACATCTGG-3'; GAPDH, forward 5'-AACGGGAAGCTTGTCATCAATGGAAA-3'; reverse 5'-GCATCAGCAGAGGGGGCAGAG-3'. PCR conditions were: $95^{\circ} \mathrm{C}$ for $5 \mathrm{~s}$ and $60^{\circ} \mathrm{C}$ for $10 \mathrm{~s} ; 40$ cycles. The cycle threshold (CT) indicated the fractional cycle number at which the PCR product was first detected above a fixed threshold. Relative mRNA levels were determined using the $2^{-\Delta \Delta \mathrm{CT}}$ method.

\subsection{Western Blotting}

HepG2 cells or 2008 cells were seeded into $75-\mathrm{cm}^{2}$ tissue culture flasks with a cell density of $1.0 \times 10^{6}$ per flask at $0 \mathrm{~h}$ and subsequently exposed to $2 \mathrm{mM} \mathrm{Mg}$ at $24 \mathrm{~h}$. Immediately after a 24-h exposure to $\mathrm{Mg}$, the cells were harvested and washed three times with cold PBS. Membrane protein fractions of cells were extracted using a plasma membrane protein extraction kit (MBL, Tokyo, Japan) according to the manufacturer's protocols. Proteins $(20 \mu \mathrm{g})$ were subjected to SDS-PAGE and transferred to polyvinylidene difluoride membrane. The membrane was blocked with Bullet Blocking One for Western Blotting (Nacalai Tesque, Kyoto, Japan) for 1 $\mathrm{h}$ at room temperature and then incubated overnight at $4^{\circ} \mathrm{C}$ with monoclonal antibody against MRP2 (24893-1-AP, Proteintech, IL, USA), OCT1 (24617-1-AP, Proteintech), MATE1 (\#14550, Cell Signaling Technology, MA, USA), or GAPDH (10494-1-AP, Proteintech). The membrane was rinsed with PBS-T (FUJIFILM Wako Pure Chemical, Osaka, Japan) and then incubated for $1 \mathrm{~h}$ with horseradish peroxidase-conjugated anti-rabbit IgG (\#7470, Cell Signaling Technology). The membrane was washed and visualized with ECL Prime Western Blotting Detection Reagent (GE Healthcare Japan, Tokyo, Japan) according to the manufacturer's protocols. 


\subsection{Intracellular Platinum Accumulation}

HepG2 cells or 2008 cells were seeded into $75-\mathrm{cm}^{2}$ tissue culture flasks with a cell density of $1.0 \times 10^{6}$ per flask at $0 \mathrm{~h}$ and then exposed to $2 \mathrm{mM} \mathrm{Mg}$ and/or $25 \mu \mathrm{M}$ CDDP at $24 \mathrm{~h}$. Immediately after an 8-h exposure to CDDP, the cells were harvested and washed three times with cold PBS. A small portion $(5 \%)$ of the cells from each experimental group was used to determine protein content using a BCA Protein Assay Kit (Pierce, Rockford, IL, USA). The remaining cell pellets were suspended in $1.5 \mathrm{~mL}$ of a mixture of perchloric acid and $30 \%$ hydrogen peroxide in a ratio of $1: 2$ and digested for $12 \mathrm{~h}$ at $65^{\circ} \mathrm{C}$. The amount of platinum in the samples was determined using an SPS 3100 Inductively Coupled Plasma Optical Emission Spectrometer (ICP-OES, Hitachi High-Tech Science Corporation, Tokyo, Japan). The results were expressed as ng of platinum per mg of protein.

\subsection{Cytotoxicity Assay}

Cytotoxicity studies were carried out using the sulforhodamine B (SRB, Nacalai Tesque, Kyoto, Japan) microculture colorimetric assay. The assay was also used to determine cell density via cellular protein content measurement. Briefly, HepG2 cells or 2008 cells were respectively plated in 96-well plates at a density of $4.0 \times 10^{3}$ cells or $1.5 \times 10^{3}$ cells per well at $0 \mathrm{~h}$ and then exposed to 2 $\mathrm{mM} \mathrm{Mg}$ and/or several concentrations of CDDP at $24 \mathrm{~h}$. The SRB assay was carried out after $96 \mathrm{~h}$ of incubation. Subsequently, cells were fixed with $10 \%$ trichloroacetic acid in situ, washed with water, and dried. Thereafter, $0.4 \% \mathrm{SRB}$ solution in $1 \%$ acetic acid was added, and the cells were incubated at room temperature for $30 \mathrm{~min}$. The cells were
(a) MRP2
(b) OCT1
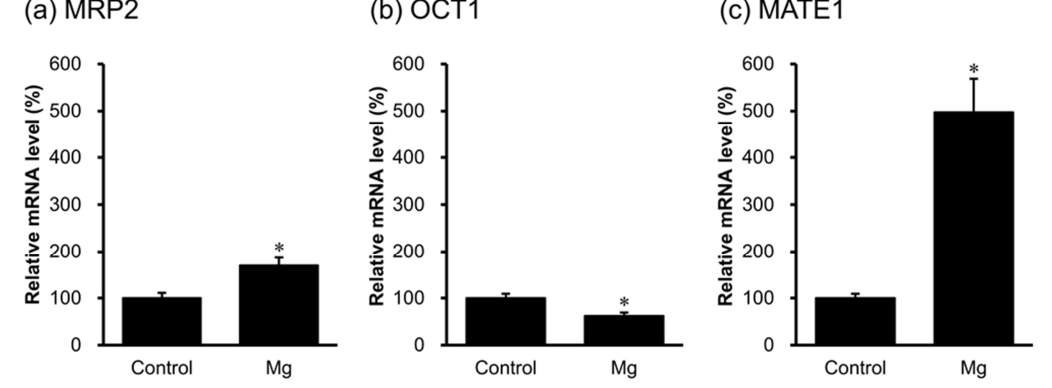

Figure 1. Relative mRNA expression levels of transporters in Hep G2 exposed to $2 \mathrm{mM}$ of $M g$ for 8 h. mRNA levels of MRP2 (a), OCT1 (b), and MATE1 (c) were normalized to that of GAPDH. The relative $m R N A$ level of each transporter is expressed as a fold increase with respect to the control group. The control group is in culture but not in contact with the drugs. Data are presented as mean $\pm S D$ of three independent experiments. ${ }^{*} p<0.05$ vs. control.
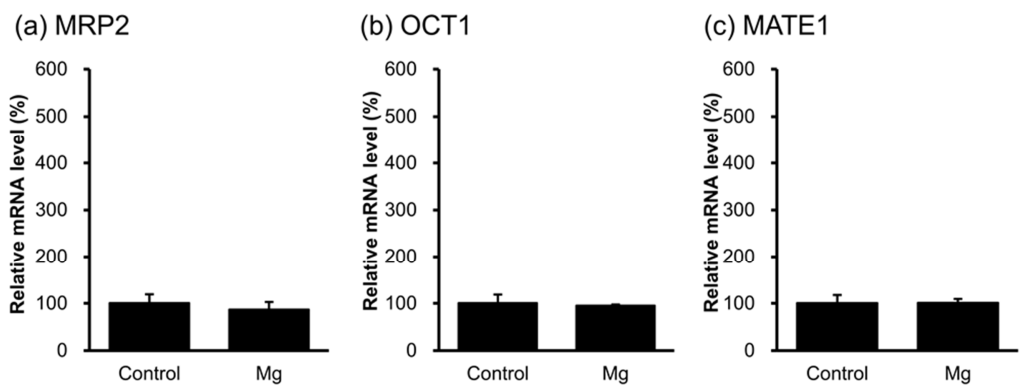

Figure 2. Relative mRNA expression levels of transporters in 2008 exposed to $2 \mathrm{mM}$ of Mg for 8 h. $m R N A$ levels of MRP2 (a), OCT1 (b), and MATE1 (c) were normalized to that of GAPDH. The relative $m R N A$ level of each transporter is expressed as a fold increase with respect to the control group. The control group is in culture but not in contact with the drugs. Data are presented as mean $\pm S D$ of three independent experiments. 


\subsection{Changes in Membrane Protein Expression Levels of Transporters Induced by Mg Exposure}

(a)

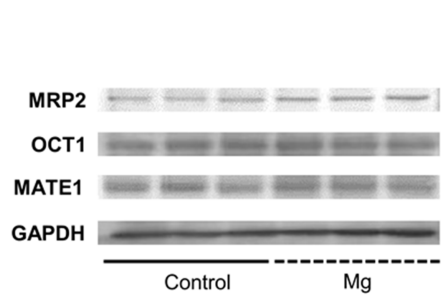

(c) OCT1

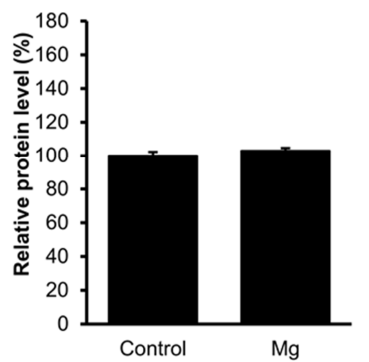

(b) MRP2

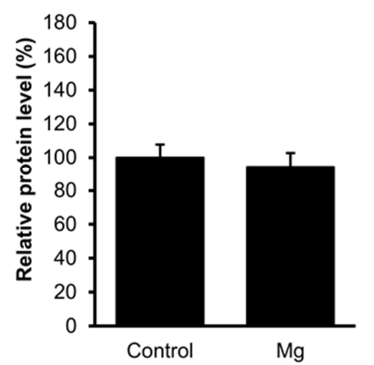

(d) MATE1

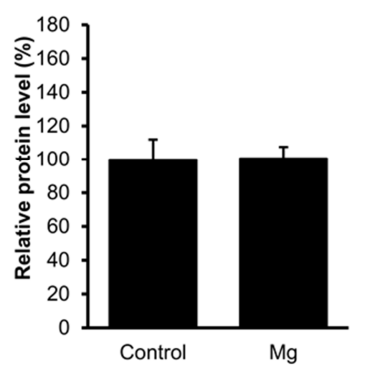

Figure 3. Relative membrane protein expression levels of transporters in Hep 22 exposed to $2 \mathrm{mM}$ of Mg for $24 \mathrm{~h}$. (a) Immunoblotting for MRP2, OCT1, and MATE1 in HepG2. Protein levels of MRP2 (b), OCT1 (c), and MATE1 (d) were normalized to that of GAPDH. Relative protein level of each transporter is expressed as a fold increase with respect to the control group. The control group is only in culture but not in contact with the drugs. Data are presented as mean $\pm S D$ of three independent experiments.

(a)

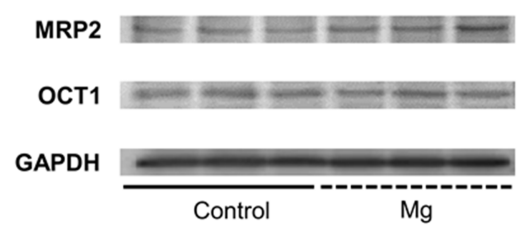

\section{(b) MRP2}

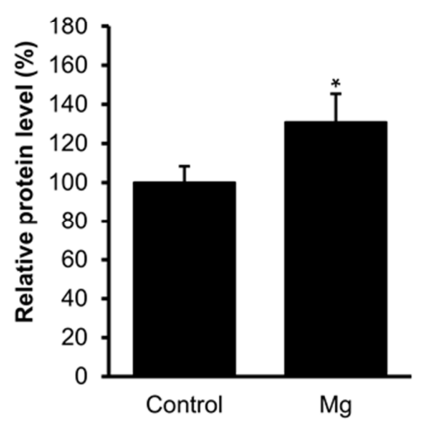

(c) OCT1

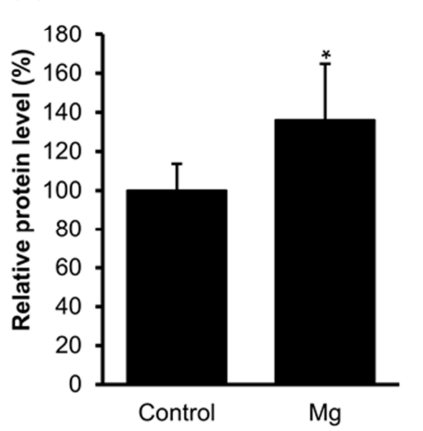

Figure 4. Relative membrane protein expression levels of transporters in 2008 exposed to $2 \mathrm{mM}$ of $\mathrm{Mg}$ for $24 \mathrm{~h}$. (a) Immunoblotting for MRP2 and OCT1 in 2008. Protein levels of MRP2 (b) and OCT1 (c) were normalized to that of GAPDH. The relative protein level of each transporter is expressed as a fold increase with respect to the control group. The control group is in culture but not in contact with the drugs. Data are presented as mean $\pm S D$ of three independent experiments. ${ }^{*} p<0.05$ vs. control.
Membrane protein levels of the transporters MRP2, OCT1, and MATE1 were measured in the HepG2 and 2008 cell lines $24 \mathrm{~h}$ after $\mathrm{Mg}$ exposure (Figures 3, 4). In HepG2 cells, no effect of $\mathrm{Mg}$ was observed on transporter expression level. Therefore, in HepG2 cells, the effect of $\mathrm{Mg}$ exposure on transporter expression differed between mRNA and protein. In 2008 cells, MATE1 protein was not detected when exposed to $\mathrm{Mg}$, both MRP2 and OCT1 expression levels were significantly increased by 1.3 -fold. Two transporters showing opposite effects in the transport of CDDP showed slight but comparable changes in expression levels.

\subsection{Effects of Mg Exposure on Intracellular Platinum and Mg Levels}

Intracellular platinum and $\mathrm{Mg}$ levels were compared in HepG2 cells exposed to Mg and/or CDDP for 8 or $24 \mathrm{~h}$ (Figure 5). Although intracellular platinum levels after CDDP exposure increased with exposure time, no effect was caused by $\mathrm{Mg}$ co-exposure. In contrast, intracellular Mg levels were slightly but significantly increased due to $\mathrm{Mg}$ exposure for $24 \mathrm{~h}$. Prolonging CDDP exposure time also resulted in a $25 \%$ decrease in intracellular Mg levels. However, in 2008 cells exposed to $\mathrm{Mg}$ for $8 \mathrm{~h}$, a difference in intracellular platinum levels was not found, while intracellular $\mathrm{Mg}$ levels were increased by approximately $30 \%$ compared to the control group exposed to CDDP alone (Figure 6). Both intracellular platinum and $\mathrm{Mg}$ levels were lower in 2008 cells than in HepG2 cells.

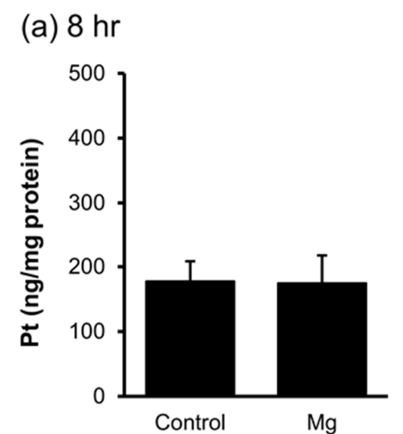

(c) $24 \mathrm{hr}$

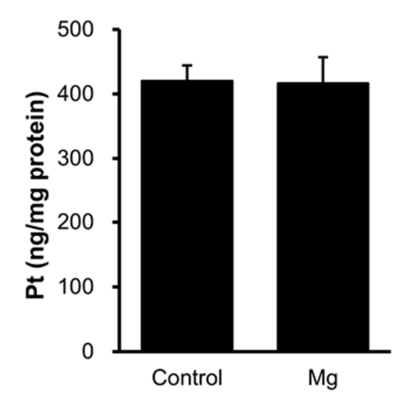

(b) $8 \mathrm{hr}$

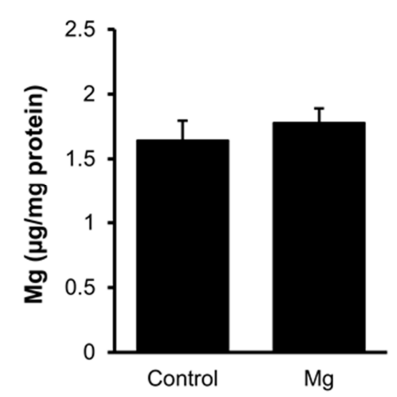

(d) $24 \mathrm{hr}$

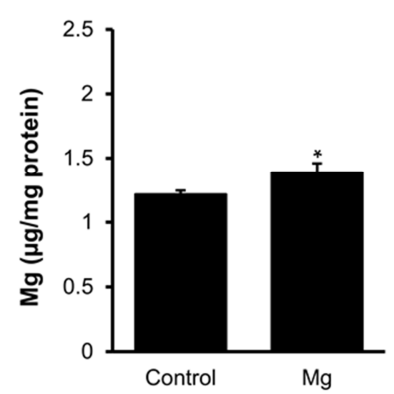

Figure 5. Intracellular platinum and $M g$ accumulation in Hep 22 exposed to $25 \mu M$ of $C D D P$ and $2 \mathrm{mM}$ of $\mathrm{Mg}$ for 8 or $24 \mathrm{~h}$. (a) Platinum levels after exposure to $C D D P$ with or without $M g$ for $8 \mathrm{~h}$, (b) Mg levels after exposure to $C D D P$ with or without $\mathrm{Mg}$ for $8 \mathrm{~h}$, (c) Platinum levels after exposure to $C D D P$ with or without $\mathrm{Mg}$ for $24 \mathrm{~h}$, and (d) $\mathrm{Mg}$ levels after exposure to $C D D P$ with or without $\mathrm{Mg}$ for $24 \mathrm{~h}$. The control group was exposed to CDDP only. Data are presented as mean $\pm S D$ of three independent experiments. ${ }^{*} p<0.05$ vs. control. 
(a)

(b)
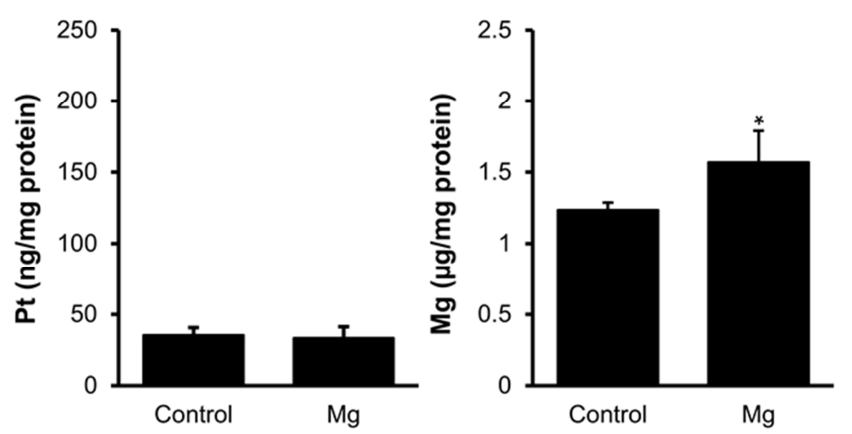

Figure 6. Intracellular platinum and Mg accumulation in 2008 exposed to 25 $\mu M$ of CDDP and $2 \mathrm{mM}$ of $\mathrm{Mg}$ for $8 \mathrm{~h}$. (a) Platinum levels after exposure to $C D D P$ with or without $\mathrm{Mg}$ for $8 \mathrm{~h}$ and (b) $\mathrm{Mg}$ levels after exposure to $\mathrm{CDDP}$ with or without $\mathrm{Mg}$ for $8 \mathrm{~h}$. The control group was exposed to CDDP only. Data are presented as mean $\pm S D$ of three independent experiments. ${ }^{*} p<0.05$ vs. control.

\subsection{Effects of Mg Exposure on CDDP Cytotoxicity}

In HepG2 and 2008 cells, the cytotoxicity of CDDP was compared between single exposure and co-exposure to $2 \mathrm{mM}$ $\mathrm{Mg}$ (Figure 7). Single exposure to $\mathrm{Mg}$ did not affect the proliferation of the cells. In fact, the respective $\mathrm{IC}_{50}$ values of CDDP were $0.79 \pm 0.04 \mu \mathrm{M}$ and $0.95 \pm 0.18 \mu \mathrm{M}$ for single exposure and combined exposure to $\mathrm{Mg}$ in $\mathrm{HepG} 2$ cells, and $1.21 \pm 0.15 \mu \mathrm{M}$ and $1.42 \pm 0.11 \mu \mathrm{M}$ in 2008 cells. These results demonstrate the lack of effect of $\mathrm{Mg}$ exposure on the cytotoxicity of CDDP.
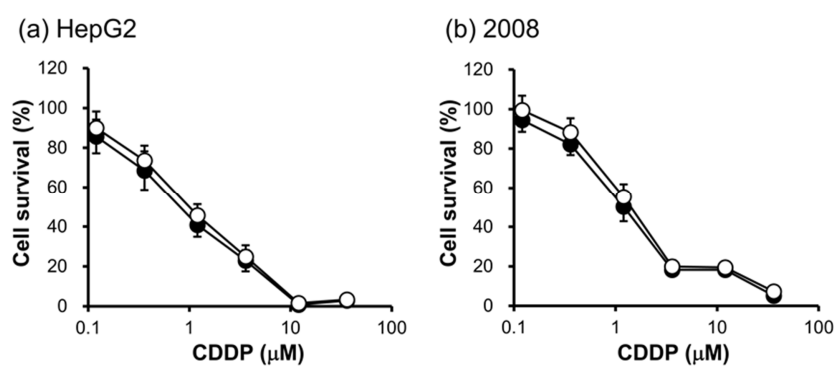

Figure 7. Effect of Mg on the cytotoxicity of CDDP in HepG2 (a) and 2008 (b) The graphs represent proliferation rates in Hep $G 2$ and 2008 cells treated with $C D D P$ and CDDP combined with $\mathrm{Mg}$. Cells were exposed to $2 \mathrm{mM}$ of $\mathrm{Mg}$ and/or CDDP for $96 \mathrm{~h}$. Cytotoxicity was assessed by the sulforhodamine $B$ assay. Opened circles: CDDP, closed circles: CDDP combined with Mg. Data are presented as mean $\pm S D$ of three independent experiments.

\section{Discussion}

Renal injury is a dose-limiting toxic effect of CDDP. Hence, infusions and diuretics are administered to reduce nephrotoxicity. Nephrotoxicity by CDDP is alleviated using massive quantities of infusion but cannot be completely avoided. In vitro studies have shown that CDDP is a substrate for human OCT2, which is involved in the accumulation of CDDP in proximal tubular cells [17]. In a study with Mate1-deficient mice, Nakamura et al. found that Mate1 is involved in tubular injury of CDDP as it transports CDDP to the luminal side [18]. Hypomagnesemia caused by CDDP treatment leads to an increase in the accumulation of CDDP in tubular cells via the up-regulation of OCT2 [12]. Mg co-administration was reported to reduce CDDP accumulation by regulating the expression of the renal transporters, Oct2 and Mate1, thereby attenuating CDDP-induced nephrotoxicity [16]. However, the influence of prophylactic administration of $\mathrm{Mg}$ on the kinetics of CDDP in cancer cells and the antitumor effect of CDDP remain unknown. MRP2 and MATE1 have been demonstrated to be involved in the extracellular export of CDDP. Intracellular uptake of CDDP into cells occurs via both passive and active transport pathways [19]. Of the transporters involved in the uptake of CDDP, we focused on OCT1, which has been reported to contribute to CDDP transport in cancer cells such as HepG2 cells, from the OCT family that contributes to CDDP transport in the kidney.

In this study, we examined the effects of Mg exposure on the expression levels of transporters involved in CDDP transport. After HepG2 cells were supplemented with Mg, the level of uptake transporter decreased, that of efflux transporter increased, and the level change in MATE1 was remarkable. Supplementing $\mathrm{Mg}$, however, did not affect the membrane protein levels of any transporter in HepG2 cells and intracellular platinum levels after CDDP exposure were not affected by $\mathrm{Mg}$ regardless of the exposure time. As $\mathrm{Mg}$ is an essential cofactor for RNA polymerase which performs transcription [20], it can increase the transcriptional activity of mRNA. However, the reason for its great effect, particularly on MATE 1 in HepG2 cells, is unknown. MATE1 contributes to the urinary excretion of CDDP, and $\mathrm{Mg}$ exposure may lead to improved MATE1 function, especially in kidney cells. Mg was not observed to impact the mRNA levels of these transporters and intracellular platinum levels after CDDP exposure in 2008 cells were much lower than those in HepG2 cells. This result suggests that those transporters may have a lower contribution to CDDP transport in 2008 cells, unlike in HepG2 cells. Intracellular Mg levels were slightly affected by $\mathrm{Mg}$ exposure in 2008 cells. Because $\mathrm{Mg}$ is a constitutive element, changes in extracellular Mg levels by several folds may not display large changes in intracellular $\mathrm{Mg}$ levels. Nonetheless, it is well-known that the transport of either substance is suppressed competitively or noncompetitively when substances transported by the same transporter coexist. CDDP uptake by the copper transporter, SLC31A1, was reported to not be affected when the coexistent copper concentration is low but is increased when the concentration is greater than or equal to $500 \mu \mathrm{M}[21,22]$. In this study, the additional application of the constitutive element, $\mathrm{Mg}$, might not have affected the transport of CDDP and the intracellular $\mathrm{Mg}$ levels. Conversely, prolonged exposure to CDDP reduced intracellular Mg levels in HepG2 cells. The SLC41 family has recently attracted attention as an $\mathrm{Mg}$ transporter [23, 24], and CDDP may influence SLC41 expression. Co-exposure of $\mathrm{Mg}$ did not affect the cytotoxicity of CDDP in HepG2 and 2008 cells. As the $\mathrm{Mg}$ concentration used in vitro was the highest plasma concentration assumed by Mg loading, it is extremely unlikely that this loading in a clinical regimen will affect the antitumor effect of CDDP. 


\section{Conclusion}

In this study, we determined the transporter expression, intracellular accumulation, and antitumor activity of CDDP in cells supplemented with $\mathrm{Mg}$. Although $\mathrm{Mg}$ exposure increased MATE1 mRNA levels, it did not affect transporter protein expression and intracellular platinum levels. Furthermore, a difference with or without $\mathrm{Mg}$ exposure was not found for CDDP cytotoxicity. These results indicate that supplementing $\mathrm{Mg}$ is not only effective in avoiding CDDP nephrotoxicity, but such supplementation does not affect the clinical effects of CDDP. Further studies on the optimal dosages and methods used by $\mathrm{Mg}$ to prevent CDDP nephrotoxicity are required.

\section{Acknowledgements}

We would like to thank Editage (www.editage.jp) for English language editing.

\section{References}

[1] Cvitkovic E, Spaulding J, Bethune V, Martin J, Whitmore WF (1977) Improvement of cis-dichlorodiammineplatinum (NSC 119875): therapeutic index in an animal model. Cancer 39: $1357-1361$.

[2] Finley RS, Fortner CL, Grove WR (1985) Cisplatin nephrotoxicity: a summary of preventative interventions. Drug Intell Clin Pharm 19: 362-367.

[3] Lajer H, Daugaard G (1999) Cisplatin and hypomagnesemia. Cancer Treat Rev 25: 47-58.

[4] Lajer H, Kristensen M, Hansen HH, Nielsen S, Frøkiaer J, Ostergaard LF, Christensen S, Daugaard G, Jonassen TE (2005) Magnesium depletion enhances cisplatin-induced nephrotoxicity. Cancer Chemother Pharmacol 56: 535-542.

[5] Tong GM, Rude RK (2005) Magnesium deficiency in critical illness. J Intensive Care Med 20: 3-17.

[6] Hansen BA, Bruserud Ø (2018) Hypomagnesemia in critically ill patients. J Intensive Care 6: 21. https://doi.org/10.1186/s40560-018-0291-y.

[7] Goren MP (2003) Cisplatin nephrotoxicity affects magnesium and calcium metabolism. Med Pediatr Oncol 41: 186-189.

[8] van Angelen AA, Glaudemans B, van der Kemp AW, Hoenderop JG, Bindels RJ (2013) Cisplatin-induced injury of the renal distal convoluted tubule is associated with hypomagnesaemia in mice. Nephrol Dial Transplant 28: 879-889.

[9] Okuda M, Tsuda K, Masaki K, Hashimoto Y, Inui K (1999) Cisplatin-induced toxicity in LLC-PK1 kidney epithelial cells: role of basolateral membrane transport. Toxicol Lett 106: 229-235.

[10] Endo T, Kimura O, Sakata M (2000) Carrier-mediated uptake of cisplatin by the OK renal epithelial cell line. Toxicology 146 : 187-195.
[11] Yokoo S, Yonezawa A, Masuda S, Fukatsu A, Katsura T, Inui K (2007) Differential contribution of organic cation transporters, OCT2 and MATE1, in platinum agent-induced nephrotoxicity. Biochem Pharmacol 74: 477-487.

[12] Yokoo K, Murakami R, Matsuzaki T, Yoshitome K, Hamada A, Saito H (2009) Enhanced renal accumulation of cisplatin via renal organic cation transporter deteriorates acute kidney injury in hypomagnesemic rats. Clin Exp Nephrol 13: 578-584.

[13] Yonezawa A, Inui K (2011) Organic cation transporter $\mathrm{OCT} / \mathrm{SLC} 22 \mathrm{~A}$ and $\mathrm{H}(+)$ /organic cation antiporter MATE/SLC47A are key molecules for nephrotoxicity of platinum agents. Biochem Pharmacol 81: 563-568.

[14] Bodnar L, Wcislo G, Gasowska-Bodnar A, Synowiec A, Szarlej-Wcisło K, Szczylik C (2008) Renal protection with magnesium subcarbonate and magnesium sulphate in patients with epithelial ovarian cancer after cisplatin and paclitaxel chemotherapy: a randomised phase II study. Eur J Cancer 44: 2608-2614.

[15] Yoshida T, Niho S, Toda M, Goto K, Yoh K, Umemura S, Matsumoto S, Ohmatsu H, Ohe Y (2014) Protective effect of magnesium preloading on cisplatin-induced nephrotoxicity: a retrospective study. Jpn J Clin Oncol 44: 346-354.

[16] Saito Y, Okamoto K, Kobayashi M, Narumi K, Yamada T, Iseki $\mathrm{K}$ (2017) Magnesium attenuates cisplatin-induced nephrotoxicity by regulating the expression of renal transporters. Eur J Pharmacol 811: 191-198.

[17] Filipski KK, Loos WJ, Verweij J, Sparreboom A (2008) Interaction of Cisplatin with the human organic cation transporter 2. Clin Cancer Res 14: 3875-3880.

[18] Nakamura T, Yonezawa A, Hashimoto S, Katsura T, Inui K (2010) Disruption of multidrug and toxin extrusion MATE1 potentiates cisplatin-induced nephrotoxicity. Biochem Pharmacol 80: 1762-1767.

[19] Hall MD, Okabe M, Shen DW, Liang XJ, Gottesman MM (2008) The role of cellular accumulation in determining sensitivity to platinum-based chemotherapy. Annu Rev Pharmacol Toxicol 48: 495-535.

[20] Yang W, Lee JY, Nowotny M (2006) Making and breaking nucleic acids: two- $\mathrm{Mg}^{2+}$-ion catalysis and substrate specificity. Mol Cell 22: 5-13.

[21] Matsumoto S, Tanaka T, Kurokawa H, Matsuno K, Hayashida Y, Takahashi T (2007) Effect of copper and role of the copper transporters ATP7A and CTR1 in intracellular accumulation of cisplatin. Anticancer Res 27: 2209-2216.

[22] Akerfeldt MC, Tran CM, Shen C, Hambley TW, New EJ (2017) Interactions of cisplatin and the copper transporter CTR 1 in human colon cancer cells. J Biol Inorg Chem 22: 765-774.

[23] Sahni J, Scharenberg AM (2013) The SLC41 family of MgtE-like magnesium transporters. Mol Aspects Med 34: 620-628.

[24] de Baaij JH, Arjona FJ, van den Brand M, Lavrijsen M, Lameris AL, Bindels RJ, Hoenderop JG (2016) Identification of SLC41A3 as a novel player in magnesium homeostasis. Sci Rep 6: 28565. https://doi.org/10.1038/srep28565. 